\title{
Driving System of Practical Teaching System in University Mathematics from the View of Knowledge
}

\author{
Xiaobo Liu \\ School of Information Engineering, Nanjing Xiaozhuang University, Nanjing, China \\ 4487758@qq.com
}

Keywords: university mathematics, practice teaching system, driving system, view of knowledge.

\begin{abstract}
If the university mathematics teaching is divided into theoretical teaching and practical teaching, so these two different types of teaching not only perform differences on teaching content and ways, but also change of the thinking way. It decides that these two types must have essential differences in view of teacher, curriculum, learning, knowledge and other aspects.
\end{abstract}

\section{Introduction}

The view of knowledge is people's general view of knowledge and ideas. The view of knowledge's essence, nature and value would directly affect the choice of teaching content and organization, in fact, it is impossible to separate education concept and knowledge concept, the view of knowledge is the basis and premise of teaching thought and theory.

\section{The Main Characteristic Of Modern View Of Knowledge}

From the contemporary study on knowledge, the view that is the most common in the philosophy is divide knowledge into theoretical knowledge and experience. Gadamer to distinguish between the three-basic knowledge, that is theoretical, practical and technology knowledge from the perspective of knowledge function. Different philosophers define knowledge and division from the different angle of view, which help us to understand the connotation and classification of knowledge, and provide the philosophical perspective to explore the nature of the practice teaching in the process of knowledge. Knowledge view of the people is always evolving and transforming. The historical evolution of knowledge form influences the existence form of knowledge, subject setting and the value of knowledge in the education through the knowledge view.

Contemporary knowledge view is the important basis of reconstructing practice education teaching system. The traditional view of knowledge separate people and the world. Contemporary knowledge view makes knowledge from reflecting the objectification of the objective world to focus on the world what the people are in, and it has the following features:

First, it is from rational factors emphasizing objective to construction actively emphasizing the main body. Knowledge is no longer regarded as the absolute reality of knowledge, and it is fluid, is actively constructed by the cognitive subject, is the understanding and cooperation between the main body, is communication and dialogue between subject and object, and is an action ability in practice.

Knowledge is not purely objective reflection of reality, also is not the accurate characterization of objective reality, it is a kind of understanding, a hypothesis, so should not be passed to students by outside forces, but need students actively construct their knowledge. Therefore, constructivism emphasizes learning is processing external information actively to get own meaning according to your own experience background.

Second, it emphasizes from on one-way function to interaction between subject and object. The process of acquiring knowledge is no longer a one-way action between subject and object, but the interaction process between human beings and the world, knowledge is the product of interaction between human beings and the world, is the world what people live in, the irrational factors such as emotion, will and interest involved. 
Third, it emphasizes from objective facts to the value relevance of knowledge. In the traditional view of knowledge, knowledge is described by specific conceptual category and proposition, embodied in the concept, principle and formula, etc. In the contemporary knowledge view, the knowledge and the interest, benefit, degree of knowledge, values and living environment of the knower are inseparable, all the knowledge are saturated with value, knowledge production is the complex process of combining rational factors with irrational factors.

Fourthly, it emphasizes from explicit knowledge to tacit components of knowledge. In traditional view of knowledge, knowledge is things which can be expressing use the written language, figure, or digital formula. In contemporary knowledge view, explicit knowledge and tacit knowledge constitute the organic whole of knowledge. Tacit knowledge exists with faith, understanding, experience, intuition, feeling, understanding, and know-how, and have the form of a scenario relevance, transform, personal, behavior or action. Obtaining and mastering these knowledges are mainly through practical experience and the form of apprenticeship.

The first people who promoting the concept of "practice" from people's daily life to philosophical category is Aristotle, he divided the knowledge into theoretical knowledge, technical knowledge and practical knowledge. Theoretical knowledge is knowledge about things eternal which could be taught. Technical knowledge is based on some experience activity which was often characterized by a certain skill, and could be taught. Practical knowledge was contraposed for individual problem solving, had a certain flexibility, situational, and was not to be taught to some extent.

Fifthly, it emphasizes from the individual learning of knowledge to situated cognition. In traditional view of knowledge, knowledge could be learnt with the efforts of the individual breaking away from situation, emphasized the universality of knowledge. In contemporary knowledge view, knowledge is a connection between people and social or physical situation of attributes, and the product of the interaction, the acquisition of knowledge is dependent on the space and time, value system and language symbols and other factors.

Practical knowledge is a kind of uncertain situational knowledge compared with the theoretical knowledge, and related to the solution of the specific situation problems. The case knowledge combined with the teacher's personal experience related to teachers' practical wisdom. It could be hidden, also could be a dominant, dominant one could be taught, whereas hidden one should be learned through practice. Practical knowledge has the integrity. These characteristics have great significances for the construction of practice education teaching system.

\section{The Value Orientation Of Higher Education Teaching Reform}

For a long time, the subject system has been invented applied higher education of our country, on the teaching concept, it emphasizes the declarative knowledge, although put forward training target of training high skilled talents, but from a practical view, technicality of teaching system of is thicker, and far from applied talents training goal. In teaching organization, it emphasized on the mastery of scientific knowledge purely, and ignore the existence of the people and participation, emphasized on the master of teachers' role and ignore the students' active play. The he old and backward traditional view of knowledge caused deviation of people's understanding in applied higher education training target orientation, curriculum provision and its implementation, teachers' training and employment, the relationship between teachers and students, the education evaluation, and many other problems. It seriously affected the improvement of education quality and its long-term development, so we must implement the transformation of knowledge view from the traditional to the contemporary.

First, it should determine the education values embodying humanistic care. In contemporary knowledge view, knowledge should have righteousness accumulate rich and broad structural system, which carried on deep needs of cultivating people by society. As the employment guidance, ability standard, the view of knowledge update firstly embodies in the revolution of education concept, it is a comprehensive reform affecting the whole teaching system by view of knowledge. Teaching must not be limited to book knowledge, it should take practical activities as the carrier, cultivate individual how to get, generate new knowledge in a particular situation, and make the education's center of gravity shift from the original knowledge and ability to emotion, attitude, values, personality and 
creativity, emphasize on communication and cooperation, embody humanistic care, encourage individuals learning to learn , learn to cooperate, and learn to care about in the process of learning knowledge, and foster the individual spirit of criticism, reflection and exploration.

Secondly, it should establish view of teaching knowledge focusing on tacit knowledge. For a long time, due to the influence of the traditional view of knowledge, people always interpret knowledge as the explicit knowledge, and only saw a practical knowledge for the application level of theoretical knowledge, such as experiment, and practice. In the arrangement of the teaching, learning theory was the first, practice training was the second, so the theory is hard to digest and absorb due to perceptual knowledge and experience lack practice.

Putting forward tacit knowledge provides a new field of vision for us to recognize and explore the education teaching theory, including the selection, organization and evaluation of knowledge in working process, and reconstruction of the teaching system under the guidance of new teaching concept, mode and method. In contemporary knowledge view, knowledge not only have explicit composition, but also have implicit components. The products, services, skills, techniques and skills in the process of work are the most valuable work process knowledge. They don't be easy to imitate, copy and transfer like explicit knowledge, but they are very important to the process of work. We must pay more attention to how to realize transform teachers' knowledge in the form of the experience to students' individual experience in practice, and make students generate new knowledge through the design of the specific situations and individual practice, and weigh the proportion of theory and practice teaching, make the dominant and recessive knowledge unite effectively, promote the transformation from declarative knowledge to procedural and strategic knowledge actively.

Third, it should refactor positive and interactive cooperation between teachers and students. Teaching is a process of interaction between teachers and students, it is the unified activities of the teachers' teaching and students' learning. In contemporary knowledge view, based on understanding of the knowledge's characteristics of the "active construction", "interaction between subject and object", "situation" and "tacit", it should fully mobilize students' initiative and enthusiasm, encourage the students learn and cognize according to own experience, interests and conditions and in accordance with its own approach. Teachers should no longer see themselves as the masters of student, should play the enabler of knowledge. Both in theoretical study and skill training, it should be democracy and equal symbiosis which is positive and interactive between teachers and students of.

Fourthly, it should establish education evaluation which reflect individuation, expansibility and diversity. Current education evaluation in our country is based on the objectivity and certainty of knowledge, adopted the so-called "standardized test". In the contemporary knowledge view, we should establish the education evaluation reflecting individuation, expansibility and diversity. It focused on from results to process, and examined the change of the students from the angle of the generation, critical reflection and development, attached importance to from according to the fixed standard to individual's unique understanding and interpretation, cultivation of reflection and ability, reflecting the personalized color, and were from unified evaluation to diversified evaluation. According to the characteristics of the practice education and the specific course requirements, it can be integrated with written test, actual operation and practical experience in a variety of ways.

\section{It Should Attach Importance To Cultivate Practical Knowledge In University Mathematics Teaching}

Applied undergraduate education determined the nature of teaching was application. But due to the misleading of exam-oriented education, for a long time, many teachers have formed concept and behavior patterns with knowledge as the core. In mathematics teaching of university, whether in developing the teaching goal, or in the teaching activities, it all focus on theory teaching of the knowledge, emphasized on the interpretation of the concept, proposition and the derivation and proving of theorem, pursued logicality, preciseness, systematisms and theoretical property, emphasized not enough on practical teaching link, less focused on process of occurrence and development of mathematical knowledge, connection with real life and its applicability, seldom teach the spirit and value of mathematics. It made the students' understanding of mathematics was 
one-sided and narrow, would do nothing to cultivate the students' practical consciousness and creative thinking. It must abandon the idea of "taking theoretical knowledge as the core", and established the idea of "taking practical knowledge as the core".

\subsection{Experience knowledge background, value forming process.}

Mathematics knowledge is derived from the real world, a lot of abstract mathematical concepts and theorem has its practical background. Knowledge learning not only emphasizes the conclusion but more should pay attention to the formation process of knowledge. Teachers in teaching should restore the natural shape of knowledge production as much as possible, actively guide students to discover problems, reveal the law, forming method, let the student be from a passive receiver to the discoverer and participants of knowledge production, and inspire students' interest in study and application of knowledge. In fact, many concept, theorem and formula in the textbook can be resolved by means of observation, guessing and reasoning. In traditional textbooks, it not pay enough attention to knowledge background, the formation and evolution process. It could make up for any deficiencies in this respect through the study of the history of mathematics in teaching. In our country, it had a long history of mathematics development, and many highlights could be can introduced, such as Nine Chapters on the Mathematical Art of Liu Hui, PI of Zu Chongzhi, Yang hui's triangle and so on.

\subsection{Creating problem situation, and guiding to explore knowledge.}

Problem situation is essentially life events associating with teaching problems, problem situation is often contact between the book knowledge and the real life, good problem situation can make students more understand the use of knowledge profoundly, master the conditions and methods of knowledge application, and help to cultivate the habit and ability of mathematics application.

For example, in teaching of first $n$ items and formula of geometric progression, it could create the following situation: a ball fell to the ground from the height of the $10 \mathrm{~m}$, the height of the bounce again for each fall was the two-thirds of the height before, the question was how much is the total movement distance the ball fell from the original to the last stop? Reference is a students' familiar common situation problem, easy to hook up the students' interest in knowledge discovery, and help understand the new knowledge better.

\subsection{Comprehending mathematics value, and improving interest in practice.}

Mathematics comes from life; its charm is come from its application. Mathematics teaching should make students love math, first is to make students understand and feel the value of mathematics. By mining material from the reality, show the prototype of mathematical knowledge in the teaching, make the abstract knowledge become more specific, vivid and interesting, it could improve the interest in learning and applying mathematics. For example, in the process of teaching derivative knowledge, it could make use of rate of change to reveal the derivative concept. Through two actual problem set of gas expansion rate and high diving, it could make abstract derivative process of derivative specific and vivid. Combining with the actual case teaching, the teacher can also guide the student to study the geometric meaning and application of derivative and monotonicity of the function further through deduction and expanding. After the theory teaching of statistical knowledge, teachers can organize practice that let the student survey the number of crossing vehicles on crossroad of downtown, make statistics, and have discussion, let them to feel the importance of mathematical knowledge.

\subsection{Guiding mathematics experiment, and developing practical skills.}

Mathematical experiment is a new teaching and learning mode. It refers that the students could be with the help of some media such as computer technology in the process of acquiring mathematical knowledge or solving math problems, and apply, observe, discover, guess, and verify mathematics exploration activity in specified conditions or experimental conditions.

Mathematics experiment is divided into four stages. The first stage is the preparation before class. It let students understand the purpose and content of the experiment, interpreted the relevant 
knowledge, and to do organization and arrangement of whole experiment process. The second stage is the experimental design. It organized group discussions, established mathematical model, and designed implementation plan. The third stage is the experiment. It had computer operation according to the schemes, and solved problems with using mathematical software. Finally, the experimental conclusion. On the mathematics experiment, students witnessed the whole process of knowledge development from the observation, guess, validation, and mastering the application. A deeper understanding of the knowledge also could feel the pleasure of applying mathematics and the practice more effectively, which are of great help to cultivate their application consciousness and practice ability.

\section{Acknowledgement}

The teaching project of Nanjing Xiaozhuang University: Research on "university mathematics" practical teaching under the goal of training applied talents stage result. The faculty teaching development program of Nanjing Xiaozhuang University: Research on practice strategy of promoting the students' autonomic learning__taking higher mathematics teaching as an example.

\section{References}

[1] Liu Xiaobo, Driving system of university mathematics practice teaching system I: view of teacher, 2016 2nd International Conference on Education, Social Science, Management and Sports, December 24-25, 2016, Qingdao, China.

[2] Liu Xiaobo, Driving system of university mathematics practice teaching system I: view of curriculum, 2016 2nd International Conference on Education, Social Science, Management and Sports, December 24-25, 2016, Qingdao, China.

[3] Liu Xiaobo, Driving system of university mathematics practice teaching system I: view of learning, 2016 2nd International Conference on Education, Social Science, Management and Sports, December 24-25, 2016, Qingdao, China. 